\title{
Educação Ambiental no contexto escolar: análise dos trabalhos apresentados no Congresso Interdisciplinar em Educação, Saúde e Ambiente
}

Environmental Education in the school context: analysis of the works presented at the Interdisciplinary Congress on Education, Health and Environment

\section{COELHO, Lucas Ribeiro. Graduando em Licenciatura em Química}

Instituto Federal do Sertão Pernambucano - Campus Petrolina. Rua Maria Luiza de Araújo Gomes Cabral, S/N, João de Deus - Petrolina - Pernambuco - Brasil. CEP: 56.316-686 / Telefone: (87) 2101.4300 / E-mail: lucasribeirocoelho18@gmail.com

ALENCAR, Fernanda Cavalcante de. Doutoranda e Mestre em Ciência dos Materiais Universidade Federal do Vale do São Francisco - Campus Juazeiro. Av. Antônio Carlos Magalhães, 510, Country Club - Juazeiro - Bahia - Brasil. CEP: 48.902-300 / Telefone: (74) 2102.7609 / E-mail: nandacvalencar@gmail.com

COELHO, Roberta Maria. Especialista em Psicopedagogia Institucional e Clínica

Centro Municipal de Educação Infantil Gabriel Moreira. Rua Gercino Rodrigues de Amorim, S/N, Rajada - Petrolina - Pernambuco - Brasil. CEP: 56.345-000 / Telefone: (87) 98157.7509 / E-mail: robertacoelho-2014@hotmail.com

\begin{abstract}
AMORIM, Delza Cristina Guedes. Mestre em Educação, Cultura e Territórios Semiáridos

Instituto Federal do Sertão Pernambucano - Campus Petrolina. Rua Maria Luiza de Araújo Gomes Cabral, S/N, João de Deus - Petrolina - Pernambuco - Brasil. CEP: 56.316-686 / Telefone: (87) 2101.4300 / E-mail: delza.cristina@ifsertao-pe.edu.br
\end{abstract}

\section{RESUMO}

Esta pesquisa objetivou realizar um levantamento de discussões promovidas pelos trabalhos apresentados no I Congresso Interdisciplinar em Educação, Saúde e Ambiente (I Ciesa), a respeito da Educação Ambiental no âmbito escolar. 0 estudo ancorou-se nos pressupostos da pesquisa de natureza qualitativa e de análise documental. Para tanto, analisou-se, por meio da técnica de análise de conteúdo, os trabalhos publicados nos anais do evento resultantes de pesquisas relacionadas à Educação Ambiental no contexto escolar. Os resultados indicaram que as discussões promovidas no I Ciesa compreenderam impasses e possibilidades para trabalhar a Educação Ambiental nas escolas. A falta de contextualização dos livros didáticos com a realidade local, a carência de ações interdisciplinares e a baixa participação de professores em cursos de formação continuada em Educação Ambiental se apresentaram como impasses, enquanto que ações interventivas desenvolvidas nas escolas se mostraram como possibilidades para a promoção de espaços de sensibilização e reflexão sobre as questões ambientais. Assim, surgem novas ideias e discussões que podem contribuir para a prática da Educação Ambiental no espaço escolar.

Palavras-chave: Meio ambiente, Educação Ambiental, Espaço escolar, I Ciesa.

\section{ABSTRACT}

This research aimed to carry out a survey of the discussions about Environmental Education in the school ambit promoted in the works presented at the I Interdisciplinary Congress on Education, Health and Environment (I Ciesa). The study was based on the assumptions of qualitative research and documentary analysis. For this, the works published in the proceedings of the event resulting from 
COELHO, L. R.; ALENCAR, F. C.; COELHO, R. M.; AMORIM, D. C. G.

Educação Ambiental no contexto escolar: análise dos trabalhos apresentados no Congresso Interdisciplinar em Educação, Saúde e Ambiente

researches related to Environmental Education in the school context were analyzed using the content analysis technique. The results indicated that the discussions promoted at I Ciesa encompassed impasses and possibilities for working with Environmental Education in schools. The lack of contextualization of textbooks with local reality, the dearth of interdisciplinary actions and the low participation of teachers in continuing education courses in Environmental Education presented themselves as impasses, while interventional actions developed in schools were shown as possibilities for promotion spaces for awareness and reflection on environmental issues. Thus, new ideas and discussions arise that can contribute to the practice of Environmental Education in the school context.

Keywords: Environment, Environmental Education, School context, I Ciesa.

\section{Introdução}

As questões relacionadas ao meio ambiente devem ser consideradas como um fato que precisa ser trabalhado e discutido em diversos contextos da sociedade. Na concepção de Miranda, Miranda e Ravaglia (2010), o consumo exagerado dos recursos naturais, o desperdício e a produção de resíduos prejudiciais ao meio ambiente resultam em graves problemas ao planeta, gerando consequências e implicações na qualidade de vida dos habitantes. A ação humana é responsável pela criação de muitos problemas ambientais e, consequentemente, os seres humanos têm o dever de solucioná-los. Desse modo, percebe-se a necessidade de uma educação voltada para o meio ambiente e suas questões, como forma de evitar novos problemas ambientais e solucionar os existentes.

A Educação Ambiental, segundo o artigo $1^{\circ}$ da Lei n. ${ }^{\circ}$ 9.795, de 27 de abril de 1999, é entendida como os processos que viabilizam a construção de valores sociais, conhecimentos, habilidades, atitudes e competências voltadas para a conservação e sustentabilidade do meio ambiente, bem de uso comum da população, essencial à sadia qualidade de vida (BRASIL, 1999). 0 objetivo da Educação Ambiental é conscientizar os cidadãos de que os problemas ambientais só podem ser resolvidos com a participação ativa, possibilitando o desenvolvimento de atitudes para o exercício da cidadania, promovendo a conscientização e o envolvimento das pessoas em atividades em defesa da sustentabilidade do planeta (OLIVEIRA; NEIMAN, 2020).

Nessa perspectiva, evidencia-se a importância de trabalhar a Educação Ambiental nas escolas, uma vez que o espaço escolar pode ser considerado um dos locais onde o aluno, no processo de formação para a cidadania, receberá os primeiros estímulos e orientações para a promoção da sua conscientização no que diz respeito aos cuidados com o meio ambiente. É na instituição escolar que o aluno dará continuidade ao processo educativo iniciado em casa com a família e, portanto, possui um papel importante no que tange ao processo de formação tanto social, quanto ambiental dos estudantes (SILVA; BEZERRA, 2016).

Os trabalhos relacionados à Educação Ambiental nas escolas devem objetivar a sensibilização e a conscientização dos educandos, mas, para isso, os conteúdos ambientais devem permear todas as áreas do conhecimento e ser contextualizados com a realidade local. Assim, a escola ajudará o discente a perceber a ligação dos fatos e a ter uma visão crítica e reflexiva do mundo em que vive. Nessa ótica, a abordagem precisa ser realizada de forma sistemática e transversal, em todos os níveis de ensino, assegurando a presença da dimensão ambiental de modo interdisciplinar, contemplando, 
COELHO, L. R.; ALENCAR, F. C.; COELHO, R. M.; AMORIM, D. C. G.

Educação Ambiental no contexto escolar: análise dos trabalhos apresentados no Congresso Interdisciplinar em Educação, Saúde e Ambiente

na prática, as atividades dos diversos componentes curriculares que compõem o currículo das escolas (ASANO; POLETTO, 2017).

Para Santos e Cavalcante (2019), apesar de a Educação Ambiental ser uma abordagem bastante propagada atualmente, ainda é pouco difundida no espaço oferecido pelas escolas. Os autores defendem que, para levantar esforços e preservar a natureza, é preciso, antes de tudo, conhecer processos que viabilizem tais ações. Sendo assim, a apropriação da Educação Ambiental no cenário educacional apresenta-se como uma ferramenta importante para atenuar os problemas ambientais.

De acordo com Ferreira (2013, p. 187), a “[...] importância da inclusão da Educação Ambiental nas escolas é salientada em uma série de trabalhos consultados na bibliografia". Nesse sentido, compreende-se que essa temática tem sido o foco de investigação de diversas pesquisas desenvolvidas na área de Educação em Meio Ambiente, cujas discussões estão apresentadas em teses, dissertações, livros, artigos de revistas científicas e trabalhos apresentados e publicados em anais de eventos científicos, como é o caso do I Congresso Interdisciplinar em Educação, Saúde e Ambiente (I Ciesa).

O I Ciesa foi organizado no âmbito do Programa de Pós-Graduação em Formação de Professores e Práticas Interdisciplinares (PPGFPPI) - Mestrado Profissional em Educação - da Universidade de Pernambuco (UPE), Campus Petrolina. O evento teve como tema central educação, práticas interdisciplinares em espaços escolares e não escolares, com o objetivo de refletir sobre a educação como um processo interdisciplinar inserido não apenas em espaços convencionalmente escolares, mas, sobretudo, reconhecendo os ambientes não escolares como potenciais locais de vivências de práticas educativas, proporcionando reflexões sobre problemas referentes à educação e sua relação com a saúde e o ambiente (SANTOS et al. 2019).

Nesse contexto, o interesse em realizar essa pesquisa surgiu da necessidade de promover discussões que possam contribuir para que a Educação Ambiental seja, de fato, desenvolvida de forma suficiente no cenário escolar, pois, embora haja diversas pesquisas na área, Bosa e Tesser (2014) apontam que muitas dificuldades precisam ser enfrentadas para trabalhar essa temática no espaço escolar. Partindo desse pressuposto, o estudo foi norteado por esta questão-problema: quais discussões acerca da temática Educação Ambiental no contexto escolar foram difundidas nos trabalhos apresentados no I Ciesa?

Diante do exposto, supôs-se que as discussões alavancadas no evento compreenderam limitações e possibilidades concernentes à prática da Educação Ambiental dentro do contexto da escola. Portanto, definiu-se como objetivo dessa pesquisa realizar um levantamento de discussões a respeito da Educação Ambiental no âmbito escolar, a partir de uma análise dos trabalhos apresentados no I Ciesa e publicados nos anais do evento.

\section{Material e métodos}

0 desenvolvimento desse trabalho pautou-se nos princípios da pesquisa de natureza qualitativa e de perspectiva documental. Na pesquisa qualitativa, os dados coletados são analisados 
COELHO, L. R.; ALENCAR, F. C.; COELHO, R. M.; AMORIM, D. C. G.

Educação Ambiental no contexto escolar: análise dos trabalhos apresentados no Congresso Interdisciplinar em Educação, Saúde e Ambiente

indutivamente, tendo o processo e seu significado como os focos principais de abordagem, não necessitando de tratamento estatístico (PRODANOV; FREITAS, 2013). Sendo de caráter documental, a pesquisa consiste na análise de materiais de natureza diversa, que ainda não receberam um tratamento analítico, ou que podem ser reexaminados, buscando interpretações novas e/ou complementares (GODOY, 1995).

O corpus de análise do estudo foi delimitado a partir dos resumos expandidos apresentados no I Ciesa, que constam no livro digital Anais do I Congresso Interdisciplinar em Educação, Saúde e Ambiente e Educação, Práticas Interdisciplinares em Espaços Escolares e não Escolares, publicado em 2019 pela Editora da Universidade de Pernambuco (Edupe). O nono eixo do evento, Educação Ambiental, foi o foco de análise desse trabalho e contém 18 resumos expandidos resultantes de pesquisas nessa área temática.

Buscando responder ao problema e alcançar o objetivo proposto, adotou-se a análise de conteúdo baseada nos pressupostos teóricos de Bardin (2011), envolvendo três fases para a sua condução: a pré-análise (fase de organização), a exploração do material (fase de categorização) e o tratamento dos resultados (fase de inferência e interpretação). Nesse escopo, a análise de conteúdo apresenta-se como um conjunto de técnicas de análise das comunicações, que são o objeto de investigação, adotando procedimentos que permitem descrever e compreender o conteúdo das mensagens.

$\mathrm{Na}$ primeira fase, visando identificar trabalhos relacionados à Educação Ambiental no contexto escolar e assegurar o controle seletivo do corpus, realizou-se a leitura completa dos resumos expandidos apresentados no nono eixo temático do evento. Nessa fase, alguns trabalhos não foram selecionados, em decorrência de apresentarem resultados de pesquisas de campo ou experimentais, sem relação com o âmbito escolar. A partir disso, selecionou-se 10 trabalhos dos 18 apresentados no eixo Educação Ambiental. Posteriormente, cada um dos resumos recebeu um código de identificação (A1 a A10), conforme detalhamento apresentado no Quadro 1.

Quadro 1 - Detalhamento dos resumos expandidos apresentados no eixo Educação Ambiental do I Ciesa, em 2019, constituintes do corpus do estudo.

\begin{tabular}{|l|l|l|}
\hline Código do trabalho & \multicolumn{1}{|c|}{ Título do trabalho } & \multicolumn{1}{|c|}{ Autoria do trabalho } \\
\hline A1 & $\begin{array}{l}\text { Ações de Educação Ambiental } \\
\text { desenvolvidas para a comunidade escolar } \\
\text { do município de Estância - Sergipe }\end{array}$ & Márcia Maria de Jesus Santos \\
\hline A2 & $\begin{array}{l}\text { Dificuldades na abordagem de temáticas } \\
\text { locais sobre caatinga nas comunidades de } \\
\text { sequeiro da rede municipal de Petrolina-PE }\end{array}$ & $\begin{array}{l}\text { Francisco das Chagas Coelho } \\
\text { Rodrigues e Antônio Marcos dos } \\
\text { Santos }\end{array}$ \\
\hline A3 & $\begin{array}{l}\text { Do ensino à prática: a utilização dos jogos } \\
\text { no processo de ensino-aprendizado dos } \\
\text { impactos ambientais }\end{array}$ & Ana Júlia de Souza Amorim \\
\hline
\end{tabular}




\begin{tabular}{|c|c|c|}
\hline \multicolumn{3}{|c|}{$\begin{array}{l}\text { COELHO, L. R.; ALENCAR, F. C.; COELHO, R. M.; AMORIM, D. C. G. } \\
\text { Educação Ambiental no contexto escolar: análise dos trabalhos apresentados no Congresso Interdisciplinar em Educação, Saúde e Ambiente }\end{array}$} \\
\hline A4 & $\begin{array}{l}\text { Educação Ambiental como viés para } \\
\text { garantia do direito ao meio ambiente } \\
\text { ecologicamente equilibrado }\end{array}$ & 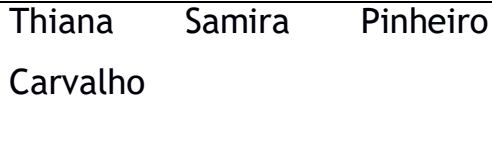 \\
\hline A5 & $\begin{array}{l}\text { Educação Ambiental no cotidiano escolar: } \\
\text { um relato de experiência }\end{array}$ & $\begin{array}{l}\text { Lucas Ribeiro Coelho e Wiris } \\
\text { Carla Souza da Silva }\end{array}$ \\
\hline A6 & $\begin{array}{l}\text { Formação continuada em Educação } \\
\text { Ambiental e qualificação de docentes do } \\
\text { ensino médio estadual da cidade de } \\
\text { Juazeiro/BA }\end{array}$ & $\begin{array}{l}\text { Charle Jean Alves da Silva e } \\
\text { Maryluce Albuquerque da Silva } \\
\text { Campos }\end{array}$ \\
\hline A7 & $\begin{array}{l}\text { Interesse de alunos do ensino fundamental } \\
\text { II, da Escola Municipal Jacob Ferreira, em } \\
\text { montar e manter horta suspensa }\end{array}$ & Vanea Martins Araújo Campos \\
\hline A8 & $\begin{array}{l}\text { Kit didático com foco na educação } \\
\text { contextualizada com o semiárido }\end{array}$ & $\begin{array}{l}\text { Marlúcia Ribeiro Sobrinho e } \\
\text { Adinoraide Santos Oliveira }\end{array}$ \\
\hline A9 & $\begin{array}{l}\text { Práticas interdisciplinares de Educação em } \\
\text { Meio Ambiente na Educação de Jovens e } \\
\text { Adultos }\end{array}$ & $\begin{array}{l}\text { Elisa Angélica Alves Guedes e } \\
\text { Edenise Gláucia Alves Guedes }\end{array}$ \\
\hline A10 & $\begin{array}{l}\text { Práticas pedagógicas em } \text { Educação } \\
\text { Ambiental: uma análise de projetos } \\
\text { políticos pedagógicos de escolas estaduais } \\
\text { de Casa Nova Bahia }\end{array}$ & $\begin{array}{l}\text { Ana Cláudia } \\
\text { Fernandes }\end{array}$ \\
\hline
\end{tabular}

Fonte: Elaborado pelos autores (2020).

Na segunda fase, após leitura detalhada do material selecionado, os textos foram organizados em três categorias, que foram produzidas de acordo com a natureza das pesquisas, a saber: pesquisa bibliográfica ou documental, pesquisa de campo e pesquisa de intervenção. Apesar de serem diferentes, as pesquisas bibliográfica e documental foram consideradas como uma única categoria, pois apresentam semelhanças e as diferenças não comprometeram a análise realizada nesse estudo. $\mathrm{Na}$ terceira fase, ocorreu a interpretação por meio da organização dos dados obtidos na análise dos textos incluídos em cada categoria, acompanhada de discussões qualitativas, considerando a relação com estudos já desenvolvidos sobre a temática.

\section{Resultados e discussão}

Nesta seção, os achados serão apresentados e discutidos de acordo com as categorias de análise: pesquisa bibliográfica ou documental, pesquisa de campo e pesquisa de intervenção. Essas categorias foram definidas a partir da natureza das pesquisas que resultaram nos manuscritos analisados, com o intuito de sistematizar os trabalhos para melhor compreensão dos dados, de modo a nortear essa investigação, cujo foco é a Educação Ambiental no contexto escolar. Conforme 
COELHO, L. R.; ALENCAR, F. C.; COELHO, R. M.; AMORIM, D. C. G.

Educação Ambiental no contexto escolar: análise dos trabalhos apresentados no Congresso Interdisciplinar em Educação, Saúde e Ambiente

detalhamento mostrado no Quadro 2, a primeira e a terceira categoria apresentaram a mesma quantidade de resumos expandidos incluídos, enquanto que a minoria dos trabalhos se enquadrou na segunda categoria.

Quadro 2 - Categorias dos trabalhos constituintes do corpus do estudo.

\begin{tabular}{|l|l|l|l|}
\hline \multicolumn{1}{|c|}{ Categoria } & \multicolumn{1}{|c|}{ Descrição da categoria } & $\begin{array}{c}\text { Trabalhos incluídos } \\
\text { na categoria }\end{array}$ & $\begin{array}{c}\text { Número de } \\
\text { trabalhos }\end{array}$ \\
\hline $\begin{array}{l}\text { Pesquisa bibliográfica } \\
\text { ou documental }\end{array}$ & $\begin{array}{l}\text { Estudo sobre Educação Ambiental } \\
\text { pautado em discussões teóricas } \\
\text { e/ou análise de materiais que não } \\
\text { receberam tratamento analítico }\end{array}$ & A2, A A10 & 04 \\
\hline Pesquisa de campo & $\begin{array}{l}\text { Pesquisa exploratória realizada } \\
\text { em comunidade escolar sobre } \\
\text { Educação Ambiental }\end{array}$ & 02 \\
\hline Pesquisa de intervenção & $\begin{array}{l}\text { Estudo realizado em escola por } \\
\text { meio de ações interventivas com } \\
\text { estudantes }\end{array}$ & A1, A3, A7 e A9 & 04 \\
\hline
\end{tabular}

Fonte: Elaborado pelos autores (2020).

Na primeira categoria de análise, observou-se que os trabalhos apresentaram, por intermédio de estudos desenvolvidos sob a perspectiva bibliográfica ou documental, considerações acerca da Educação Ambiental. Em A4, Carvalho (2019) aponta, por meio de estudo bibliográfico, a necessidade de abordar a relação entre a Educação Ambiental e o uso consciente dos recursos ambientais. Embora o trabalho tenha sido apresentado em fase de desenvolvimento, a autora considerou que a valorização da Educação Ambiental nas escolas, associada à prática de reflexão, efetivação de políticas governamentais, bem como a criação de órgãos fiscalizatórios e uma legislação rígida, servirão para formar cidadãos responsáveis com as questões ambientais e seguros quanto ao exercício de seu direito de viverem em um ambiente ecologicamente equilibrado.

O estudo de Fernandes (2019), A10, foi dedicado a avaliar os projetos político-pedagógicos de escolas estaduais do município de Casa Nova-BA quanto ao tema Educação Ambiental. Na avaliação dos documentos, observou-se o tratamento do tema de forma pontual e esporádica, implicando em documentos insuficientes para atender às demandas da transversalidade, tornando-se, dessa forma, necessário a ampliação de pesquisas em Educação Ambiental do ponto de vista escolar, com respectivas intervenções para minimizar tais problemas.

Rodrigues e Santos (2019), em A2, enfatizam que, na realidade do semiárido, os temas relacionados à região são escassos nos livros didáticos e não contemplam a necessidade do educador na abordagem sobre os temas locais. Assim, o estudo, apresentado em fase de desenvolvimento, apoiou-se no propósito de analisar conteúdos voltados para a conservação da vegetação da caatinga nos livros didáticos e nos materiais paradidáticos utilizados em escolas da rede municipal de ensino 
COELHO, L. R.; ALENCAR, F. C.; COELHO, R. M.; AMORIM, D. C. G.

Educação Ambiental no contexto escolar: análise dos trabalhos apresentados no Congresso Interdisciplinar em Educação, Saúde e Ambiente

de Petrolina-PE, visando contribuir para que os professores das escolas envolvidas trabalhem práticas que estimulem os alunos a construírem conhecimentos baseados em uma realidade local, sem desconsiderar a realidade em escala regional e global.

Nesse contexto, no trabalho A8, Sobrinho e Oliveira (2019), ao analisarem a ausência de contextualização com o semiárido em livros didáticos, apresentam a elaboração de um kit didático, abordando o semiárido brasileiro e o bioma caatinga, sugerindo para discussão no âmbito escolar aportes didático-pedagógicos, tais como: músicas, desenhos animados, cartazes temáticos, jogos, dentre outras atividades. As autoras indicam que o material foi produzido para auxiliar docentes do ensino básico em relação à contextualização com o semiárido.

A partir dessa análise, inferiu-se que os trabalhos incluídos nessa categoria apontaram que a Educação Ambiental, apesar de ser necessária, não está sendo praticada de forma suficiente no trabalho desenvolvido nas escolas. Nessa linha de pensamento, estabelece-se diálogo com Bosa e Tesser (2014), ao observarem que são encontradas muitas dificuldades para trabalhar a Educação Ambiental no cenário educacional, considerando que a infraestrutura e os aspectos didáticos e metodológicos das escolas apresentam alguma ou algumas carências.

Dentre as considerações realizadas nesses trabalhos, destaca-se, sobretudo, a necessidade de contextualização com a realidade do semiárido, região onde os estudos foram desenvolvidos. Nesse escopo, o desenvolvimento contextualizado de ações de Educação Ambiental com a região semiárida, onde a vegetação predominante é a caatinga, exerce função primordial para o trabalho da dimensão ambiental, auxiliando não apenas na sensibilização da população para a conservação dos recursos naturais, como também na discussão sobre a importância da caatinga e de suas riquezas, envolvendo, também, os problemas tão recorrentes e que se apresentam ao longo da exploração desse bioma (CAMPELO; MELO, 2018).

$\mathrm{Na}$ segunda categoria de análise, notou-se que os textos se apoiaram em resultados de pesquisas de campo exploratórias realizadas em comunidades escolares. Em A5, Coelho e Silva (2019) relatam que, apesar de poucos recursos, uma escola estadual de ensino médio de Petrolina-PE realiza atividades, por intermédio de uma disciplina eletiva, que estimulam a conscientização e boas práticas nos estudantes, concluindo que a Educação Ambiental é tratada, no ambiente pesquisado, como um tema capaz de proporcionar debates importantes e ações de conservação do meio ambiente, embora careça de ampliar as ações de forma interdisciplinar.

Diante disso, sob a visão de Giassi et al. (2016), a ampliação das ações com caráter interdisciplinar pode possibilitar aos alunos relações entre aspectos físicos, químicos, biológicos, sociais e de outras áreas do conhecimento, norteando, assim, a interdisciplinaridade e ampliando o entendimento dos estudantes. Desse modo, a abordagem interdisciplinar das questões ambientais implica na utilização das contribuições dos diversos componentes curriculares para se construir a compreensão e a explicação do problema tratado e, dessa maneira, superar a compartimentação (MIRANDA; MIRANDA; RAVAGLIA, 2010).

Silva e Campos (2019), autores de A6, visaram identificar a participação de professores, do ensino médio estadual de Juazeiro-BA, em cursos de formação continuada em Educação Ambiental e 
COELHO, L. R.; ALENCAR, F. C.; COELHO, R. M.; AMORIM, D. C. G.

Educação Ambiental no contexto escolar: análise dos trabalhos apresentados no Congresso Interdisciplinar em Educação, Saúde e Ambiente

conhecer a qualificação profissional dos docentes. Como resultado, evidenciou-se que, embora um número considerável de professores possua curso de pós-graduação, há baixa participação da população estudada em cursos e oficinas em Educação Ambiental. Sob essa perspectiva, a falta de participação dos docentes em cursos de formação continuada pode ser um empecilho para que, de fato, a Educação Ambiental se efetive e seja praticada no ambiente escolar.

Nesse sentido, Asano e Poletto (2017) afirmam a necessidade de proporcionar aos educadores condições para que possam trabalhar temas e atividades de Educação Ambiental, conduzindo as práticas, materiais, guias e projetos, ambos de cunho pedagógico, que incentivem o debate, a reflexão sobre as questões ambientais e a construção de uma consciência crítica. Florentino e Abílio (2016) acrescentam que o processo de formação continuada em Educação Ambiental possibilita reflexão acerca do planejamento e da prática pedagógica, auxiliando a construção de novos significados e oferecendo caminhos e possibilidades para a inserção da temática nas escolas, de maneira interdisciplinar e contextualizada.

$\mathrm{Na}$ terceira categoria de análise, verificou-se que os estudos foram realizados mediante ações interventivas, envolvendo estudantes de escolas públicas. Em A1, Santos (2019) objetivou contribuir, por meio da oferta de palestras, oficinas e minicursos, para o estímulo de práticas de Educação Ambiental para além dos muros da escola, a partir da integração entre escola e comunidade externa, evidenciando mudanças de valores nos sujeitos envolvidos, tais como: mudanças de comportamentos diante da temática socioambiental, como também a preservação do meio ambiente, alcançando a dispersão de novos hábitos sustentáveis, no âmbito escolar interno e externo.

Amorim (2019), autora do resumo expandido A3, desenvolveu e aplicou um jogo manual no processo de ensino-aprendizagem de Geografia, acompanhado de discussões sobre impactos ambientais em escala local, regional e nacional, em uma escola do município de Petrolina-PE. Como resultado, notou-se a sensibilização dos discentes quanto à contribuição antrópica e à necessidade de buscar uma vida mais sustentável, reconhecendo a responsabilidade da ação humana, bem como a necessidade de mudança no comportamento da sociedade.

No estudo A7, Campos (2019) se propôs a investigar o interesse de estudantes de uma escola municipal de Petrolina-PE em montar e manter uma horta suspensa. A pesquisa permitiu constatar que os alunos envolvidos interagiram e participaram das atividades interventivas propostas, declarando interesse em efetivar o cultivo e a manutenção da horta suspensa, reutilizando garrafas de polietileno tereftalato (garrafas PET) e utilizando resíduos orgânicos recolhidos no preparo da merenda escolar para a fabricação de adubo orgânico.

Em A9, Guedes e Guedes (2019) trabalharam a Educação Ambiental por meio de oficinas temáticas interdisciplinares com alunos da Educação de Jovens e Adultos (EJA), em uma escola de Petrolina-PE, dentro das disciplinas de Biologia e Português. Percebeu-se a aquisição de conhecimentos quanto à escrita nos produtos desenvolvidos durante as oficinas, assim como o envolvimento dos alunos em discussões somado à postura crítica com potencial para mudança de atitude em suas reflexões sobre as questões ambientais abordadas. 
COELHO, L. R.; ALENCAR, F. C.; COELHO, R. M.; AMORIM, D. C. G.

Educação Ambiental no contexto escolar: análise dos trabalhos apresentados no Congresso Interdisciplinar em Educação, Saúde e Ambiente

Dessa forma, essa discussão a respeito do desenvolvimento de intervenções pedagógicas em Educação Ambiental engloba a sugestão de Fernandes (2019), no trabalho A10, sobre a realização de estudos do ponto de vista escolar, acompanhados de intervenções. Tais atividades interventivas compreenderam a utilização de jogos, oficinas, minicursos e montagem de horta, possibilitando a sensibilização e reflexão acerca de questões ambientais aos estudantes envolvidos. Nesse entendimento, Santos e Cavalcante (2019, p. 84) relatam que os momentos de intervenção são capazes de moldar a "[...] formação de educandos comprometidos com a preservação ambiental e apropriação de uma postura de agentes transformadores da realidade".

Esse pensamento vai ao encontro de Giassi et al. (2016), ao considerarem que o papel da educação na compreensão de questões ambientais deve ser norteado para proporcionar que a escola se torne um espaço de sensibilização e capacitação de alunos para uma tomada de consciência e aquisição de conhecimentos que viabilizem a integração do indivíduo com a comunidade. Assim, caminha-se para a formação de cidadãos capazes de enfrentar os desafios da sociedade atual, cujo grande dilema gira na solução dos problemas ambientais.

Portanto, os achados apresentados nesse estudo estão de acordo com a perspectiva de Ferreira (2013, p. 187), uma vez que a “[...] Educação Ambiental sozinha não conseguirá transformar a sociedade, mas ela pode ser o ponto de partida para incentivar reflexões e ações que contribuam para diminuir os danos ambientais”. Assim, surgem, no espaço oferecido pela comunidade escolar, novas ideias e discussões que podem contribuir para a formação de sujeitos críticos e ativos na construção de sociedades sustentáveis (FERREIRA, 2013).

\section{Conclusões}

A finalidade desse estudo foi levantar discussões relacionadas à Educação Ambiental no contexto escolar difundidas nos trabalhos apresentados no I Ciesa. Os resultados da análise dos resumos expandidos publicados nos anais do evento apontaram que, por meio da realização de pesquisas de diferentes naturezas, foram promovidas discussões que demonstraram limitações e possibilidades para trabalhar a Educação Ambiental no ambiente escolar.

Evidenciou-se que os trabalhos resultantes de pesquisas bibliográfica, documental e de campo discutiram os seguintes aspectos como impasses para a prática da Educação Ambiental nas escolas: falta de contextualização dos livros didáticos com a realidade local, carência de ações interdisciplinares e baixa participação de professores em cursos de formação continuada sobre a temática. Tais dilemas resultam na prática insuficiente da Educação Ambiental dentro das comunidades escolares.

Por outro lado, os trabalhos resultantes de pesquisas de intervenção apresentaram que intervenções didático-pedagógicas com foco em Educação Ambiental desenvolvidas nas escolas são possibilidades para viabilizar espaços de sensibilização e reflexão aos estudantes acerca de questões ambientais, promovendo a formação de cidadãos com potencial para mudança de comportamentos e hábitos frente aos problemas ambientais, visando à conservação do meio ambiente. 
COELHO, L. R.; ALENCAR, F. C.; COELHO, R. M.; AMORIM, D. C. G.

Educação Ambiental no contexto escolar: análise dos trabalhos apresentados no Congresso Interdisciplinar em Educação, Saúde e Ambiente

Nesse sentido, com a apresentação e publicação dos trabalhos avaliados nesse artigo, considera-se que o I Ciesa, mais especificamente o seu nono eixo temático, contribuiu para o entendimento de que a Educação Ambiental é um processo capaz de possibilitar aos envolvidos o desenvolvimento de atitudes para o exercício da cidadania, reconhecendo não somente a necessidade de cuidados com as questões ambientais, mas também pondo em prática ações em defesa da sustentabilidade do meio ambiente. Portanto, acredita-se que as ideias construídas e apresentadas nesse estudo podem fornecer subsídios para a compreensão da importância da Educação Ambiental dentro do contexto da escola.

\section{Agradecimento}

À professora Maria da Penha Luz da Gama por contribuir com a revisão textual do artigo.

\section{Referências}

AMORIM, Ana Júlia de Souza. Do ensino à prática: a utilização dos jogos no processo de ensinoaprendizado dos impactos ambientais. In: CONGRESSO INTERDISCIPLINAR EM EDUCAÇ̃̃O, SAÚDE E AMBIENTE, 1., 2019, Petrolina. Anais do I Congresso Interdisciplinar em Educação, Saúde e Ambiente e educação, práticas interdisciplinares em espaços escolares e não escolares. Recife: Edupe, 2019. p. 364-366. Disponível em: http://www.edupe.com.br/produto.php?codigo=95. Acesso em: 22 maio 2020.

ASANO, Juliete Gomes Póss; POLETTO, Rodrigo de Souza. Educação ambiental: em busca de uma sociedade sustentável, e os desafios enfrentados nas escolas. Caderno Pedagógico, Lajeado, v. 14, n. 1, p. 92-102, 2017. Disponível em:

http://www.univates.br/revistas/index.php/cadped/article/view/1418/1168. Acesso em: 18 jun. 2020.

BARDIN, Laurence. Análise de conteúdo. São Paulo: Edições 70, 2011.

BOSA, Cláudia Regina; TESSER, Halandey Camilo de Borba. Desafios da escola ambiental nas escolas municipais do município de Caçador-SC. Revista Monografias Ambientais, Santa Maria, v. 14, n. 2, 2996-3010, mar. 2014. Disponível em: https://periodicos.ufsm.br/remoa/article/view/9763/pdf. Acesso em: 17 jun. 2020.

BRASIL. Lei $n .^{\circ}$ 9.775, de 27 de abril de 1999. Dispõe sobre a educação ambiental, institui a Política Nacional de Educação Ambiental e dá outras providências. Brasília: Presidência da República, 1999. Disponível em: http://www.planalto.gov.br/ccivil_03/leis/l9795.htm. Acesso em: 13 jun. 2020.

CAMPELO, Ana Karine Ribeiro; MELO, Juliana Barroso de. A importância de projetos de educação ambiental em uma unidade de conservação no semiárido nordestino. Revista Brasileira de Ciências Ambientais, n. 49, p. 81-94, set. 2018. Disponível em: http://rbciamb.com.br/index.php/Publicacoes_RBCIAMB/article/view/39/468. Acesso em: 16 jun. 2020.

CAMPOS, Vanea Martins Araújo. Interesse de alunos do ensino fundamental II, da Escola Municipal Jacob Ferreira, em montar e manter horta suspensa. In: CONGRESSO INTERDISCIPLINAR EM EDUCACÃO, SAÚDE E AMBIENTE, 1., 2019, Petrolina. Anais do I Congresso Interdisciplinar em Educação, Saúde e Ambiente e educação, práticas interdisciplinares em espaços escolares e não 
COELHO, L. R.; ALENCAR, F. C.; COELHO, R. M.; AMORIM, D. C. G.

Educação Ambiental no contexto escolar: análise dos trabalhos apresentados no Congresso Interdisciplinar em Educação, Saúde e Ambiente

escolares. Recife: Edupe, 2019. p. 385-387. Disponível em:

http://www.edupe.com.br/produto.php?codigo=95. Acesso em: 22 maio 2020.

CARVALHO, Thiana Samira Pinheiro. Educação ambiental como viés para garantia do direito ao meio ambiente ecologicamente equilibrado. In: CONGRESSO INTERDISCIPLINAR EM EDUCAÇÃO, SAÚDE E AMBEINTE, 1., 2019, Petrolina. Anais do I Congresso Interdisciplinar em Educação, Saúde e Ambiente e educação, práticas interdisciplinares em espaços escolares e não escolares. Recife: Edupe, 2019. p. 367-369. Disponível em: http://www.edupe.com.br/produto.php?codigo=95. Acesso em: 22 maio 2020.

COELHO, Lucas Ribeiro; SILVA, Wiris Carla Souza da. Educação ambiental no cotidiano escolar: um relato de experiência. In: CONGRESSO INTERDISCIPLINAR EM EDUCAÇÃO, SAÚDE E AMBIENTE, 1., 2019, Petrolina. Anais do I Congresso Interdisciplinar em Educação, Saúde e Ambiente e educação, práticas interdisciplinares em espaços escolares e não escolares. Recife: Edupe, 2019. p. 370-371. Disponível em: http://www.edupe.com.br/produto.php?codigo=95. Acesso em: 22 maio 2020.

FERNANDES, Ana Cláudia dos Passos. Práticas pedagógicas em educação ambiental: uma análise de projetos políticos pedagógicos de escolas estaduais de Casa Nova Bahia. In: CONGRESSO INTERDISCIPLINAR EM EDUCAÇÃO, SAÚDE E AMBIENTE, 1., 2019, Petrolina. Anais do I Congresso Interdisciplinar em Educação, Saúde e Ambiente e educação, práticas interdisciplinares em espaços escolares e não escolares. Recife: Edupe, 2019. p. 399-401. Disponível em: http:// www.edupe.com.br/produto.php?codigo=95. Acesso em: 22 maio 2020.

FERREIRA, Claudia Elisa Alves. O meio ambiente na prática de escolas públicas da rede estadual de São Paulo: intenções e possibilidades. Ambiente \& Educação, v. 18, n. 1, p. 185-2019, 2013. Disponível em: https://periodicos.furg.br/ambeduc/article/view/3100/2408. Acesso em: 20 jun. 2020.

FLORENTINO, Hugo da Silva; ABÍLIO, Francisco José Pegado. Formação continuada de professores, vivências de educação ambiental no contexto semiárido. Revista Reflexão e Ação, Santa Cruz do Sul, v. 24, n. 2, p. 334-354, maio/ago. 2016. Disponível em:

https://online.unisc.br/seer/index.php/reflex/article/view/3849/pdf. Acesso em: 19 jun. 2020.

GIASSI, Maristela Gonçalves et al. Ambiente e cidadania: educação ambiental nas escolas. Revista de Extensão, Criciúma, v. 1, n. 1, p. 24-32, 2016. Disponível em:

http://periodicos.unesc.net/revistaextensao/article/view/2461/2337. Acesso em: 19 jun. 2020.

GODOY, Arilda Schmidt. Pesquisa qualitativa: tipos fundamentais. Revista de Administração de Empresas, São Paulo, v. 35, n. 3, p. 20-29, maio/jun. 1995. Disponível em:

https://www.scielo.br/pdf/rae/v35n3/a04v35n3.pdf. Acesso em: 10 jun. 2020.

GUEDES, Elisa Angélica Alves; GUEDES, Edenise Gláucia Alves. Práticas interdisciplinares em educação em meio ambiente na educação de jovens e adultos. In: CONGRESSO INTERDISCIPLINAR EM EDUCAÇÃO, SAÚDE E AMBIENTE, 1., 2019, Petrolina. Anais do I Congresso Interdisciplinar em Educação, Saúde e Ambiente e educação, práticas interdisciplinares em espaços escolares e não escolares. Recife: Edupe, 2019. p. 396-398. Disponível em:

http://www.edupe.com.br/produto.php?codigo=95. Acesso em: 22 maio 2020.

MIRANDA, Fátima Helena da Fonseca; MIRANDA, José Arlindo; RAVAGLIA, Rosana. Abordagem interdisciplinar em educação ambiental. Revista Práxis, v. 11, n. 4, ago. 2010. Disponível em: http://revistas.unifoa.edu.br/index.php/praxis/article/view/922/972. Acesso em: 17 jun. 2020.

OLIVEIRA, Lucas de; NEIMAN, Zysman. Educação ambiental no âmbito escolar: análise do processo de elaboração e aprovação da Base Nacional Comum Curricular (BNCC). Revista Brasileira de Educação Ambiental, São Paulo, v. 15, n. 3, p. 36-52, maio 2020. Disponível em: https://periodicos.unifesp.br/index.php/revbea/article/view/10474/7735. Acesso em: 19 jun. 2020. 
COELHO, L. R.; ALENCAR, F. C.; COELHO, R. M.; AMORIM, D. C. G.

Educação Ambiental no contexto escolar: análise dos trabalhos apresentados no Congresso Interdisciplinar em Educação, Saúde e Ambiente

PRODANOV, Cleber Cristiano; FREITAS, Ernani Cesar de. Metodologia do trabalho científico: métodos e técnicas da pesquisa e do trabalho acadêmico. 2. ed. Novo Hamburgo: Feevale, 2013. Disponível em: http:/ / www.feevale.br/Comum/midias/8807f05a-14d0-4d5b-b1ad-1538f3aef538/Ebook\%20Metodologia\%20do\%20Trabalho\%20Cientifico.pdf. Acesso em: 18 maio 2020.

RODRIGUES, Francisco das Chagas Coelho; SANTOS, Antônio Marcos dos. Dificuldades na abordagem de temáticas locais sobre caatinga nas comunidades de sequeiro da rede municipal de Petrolina-PE. In: CONGRESSO INTERDISCIPLINAR EM EDUCAÇÃO, SAÚDE E AMBIENTE, 1., 2019, Petrolina. Anais do I Congresso Interdisciplinar em Educação, Saúde e Ambiente e educação, práticas interdisciplinares em espaços escolares e não escolares. Recife: Edupe, 2019. p. 361-363. Disponível em: http://www.edupe.com.br/produto.php?codigo=95. Acesso em: 22 maio 2020.

SANTOS, Antônio Marcos dos et al. Anais do I Congresso Interdisciplinar em Educação, Saúde e Ambiente e educação, práticas interdisciplinares em espaços escolares e não escolares. Recife: Edupe, 2019. Disponível em: http: / /www.edupe.com.br/produto.php?codigo=95. Acesso em: 22 maio 2020.

SANTOS, Cláudia Lilian Alves dos; CAVALCANTE, Kellison Lima. Ludicidade e aprendizagem significativa na formação de estudantes em educação ambiental: relato de experiência. Revista Semiárido De Visu, Petrolina, v. 7, n. 1, p. 73-87, 2019. Disponível em: https://periodicos.ifsertaope.edu.br/ojs2/index.php/semiaridodevisu/article/view/477/426. Acesso em: 27 jun. 2020.

SANTOS, Márcia Maria de Jesus. Ações de Educação Ambiental desenvolvidas para a comunidade escolar do município de Estância - Sergipe. In: CONGRESSO INTERDISCIPLINAR EM EDUCAÇÃO, SAÚDE E AMBIENTE, 1., 2019, Petrolina. Anais do I Congresso Interdisciplinar em Educação, Saúde e Ambiente e educação, práticas interdisciplinares em espaços escolares e não escolares. Recife: Edupe, 2019. p. 359-360. Disponível em: http://www.edupe.com.br/produto.php?codigo=95. Acesso em: 22 maio 2020.

SILVA, Charle Jean Alves da; CAMPOS, Maryluce Albuquerque da Silva. Formação continuada em educação ambiental e qualificação de docentes do ensino médio estadual de Juazeiro/BA. In: CONGRESSO INTERDISCIPLINAR EM EDUCAÇÃO, SAÚDE E AMBIENTE, 1., 2019, Petrolina. Anais do I Congresso Interdisciplinar em Educação, Saúde e Ambiente e educação, práticas interdisciplinares em espaços escolares e não escolares. Recife: Edupe, 2019. p. 377-379. Disponível em: http://www.edupe.com.br/produto.php?codigo=95. Acesso em: 22 maio 2020.

SILVA, Heloina Oliveira da; BEZERRA, Renilton Delmundes. A importância da educação ambiental no âmbito escolar. Revista Interface, n. 12, p. 163-172, dez. 2016. Disponível em: https://sistemas.uft.edu.br/periodicos/index.php/interface/article/view/2007. Acesso em: 17 jun. 2020.

SOBRINHO, Marlúcia Ribeiro; OLIVEIRA, Adinoraide Santos. Kit didático com foco na educação contextualizada com o semiárido. In: CONGRESSO INTERDISCIPLINAR EM EDUCAÇÃO, SAÚDE E AMBIENTE, 1., 2019, Petrolina. Anais do I Congresso Interdisciplinar em Educação, Saúde e Ambiente e educação, práticas interdisciplinares em espaços escolares e não escolares. Recife: Edupe, 2019. p. 390-391. Disponível em: http://www.edupe.com.br/produto.php?codigo=95. Acesso em: 22 maio 2020. 